\title{
Laboratory observation of oligomers in the aerosol from isoprene/ $\mathrm{NO}_{\mathrm{x}}$ photooxidation
}

\author{
J. Dommen, ${ }^{1}$ A. Metzger, ${ }^{1}$ J. Duplissy, ${ }^{1}$ M. Kalberer, ${ }^{2}$ M. R. Alfarra, ${ }^{1}$ A. Gascho, ${ }^{1}$ \\ E. Weingartner, ${ }^{1}$ A. S. H. Prevot, ${ }^{1}$ B. Verheggen,${ }^{1}$ and U. Baltensperger ${ }^{1}$ \\ Received 7 April 2006; revised 5 May 2006; accepted 30 May 2006; published 6 July 2006.
}

[1] Compounds assigned to be oxidation products of isoprene (2-methyl-1,3-butadiene) have recently been observed in ambient aerosols, suggesting that isoprene might play an important role in secondary organic aerosol (SOA) formation due to its large global source strength. SOA yields from photooxidation of isoprene and $\mathrm{NO}_{\mathrm{x}}$ in a chamber agree fairly well with previous data. Matrix assisted laser desorption/ionization mass spectrometry showed the formation of high molecular weight compounds over the course of 15-hour experiments. Concurrently, the volatility of the SOA decreased markedly as observed by a tandem differential mobility analyzer. The volume fraction remaining of $\mathrm{SOA}$ at $150^{\circ} \mathrm{C}$ increased steadily from 5 to $25 \%$ during the same experiments. These observations are attributed to oligomerization reactions occurring in the aerosol phase. Under dry conditions a lower volatility was observed. Citation: Dommen, J., A. Metzger, J. Duplissy, M. Kalberer, M. R. Alfarra, A. Gascho, E. Weingartner, A. S. H. Prevot, B. Verheggen, and U. Baltensperger (2006), Laboratory observation of oligomers in the aerosol from isoprene/ $\mathrm{NO}_{\mathrm{x}}$ photooxidation, Geophys. Res. Lett., 33, L13805, doi:10.1029/ 2006 GL026523.

\section{Introduction}

[2] The contribution of isoprene to secondary organic aerosol (SOA) formation has long been considered to be relatively unimportant. However, based on observations of tetrols [Claeys et al., 2004; Edney et al., 2005] and other isoprene oxidation products [Matsunaga et al., 2005] in ambient PM2.5 it was recently proposed that isoprene could substantially contribute to SOA formation. Isoprene is one of the most abundant non-methane hydrocarbons emitted into the troposphere with a source strength of $\sim 500 \mathrm{Tg} /$ year [Guenther et al., 1995], therefore even low SOA yields may have a large impact on SOA formed both regionally and globally.

[3] The main oxidation products of isoprene have been identified and their yields determined. Because of the relatively high volatility of these products they were not considered to contribute significantly to the formation of SOA. In the study of Kamens et al. [1982] the isopreneozone system produced homogenously nucleated aerosol at 4 ppm isoprene with a yield of less than $1 \%$, but no

\footnotetext{
${ }^{1}$ Laboratory of Atmospheric Chemistry, Paul Scherrer Institut, Villigen, Switzerland.

${ }^{2}$ Department of Chemistry and Applied Biosciences, Swiss Federal Institute of Technology (ETH) Zurich, Zurich, Switzerland.

Copyright 2006 by the American Geophysical Union. 0094-8276/06/2006GL026523
}

nucleation occurred during the reaction of low concentrations of isoprene. Similarly, Pandis et al. [1991] observed a yield of $1 \%$ above $1 \mathrm{ppm}$ but insignificant aerosol growth below. Limbeck et al. [2003] showed that heterogeneous reactions of isoprene under highly acidic conditions lead to the formation of macromolecular, humic-like substances. A recent study by Edney et al. [2005] gave a 14-fold increased yield of SOA from isoprene photooxidation when $268 \mathrm{ppb}$ of $\mathrm{SO}_{2}$ was added to $1680 \mathrm{ppb}$ of isoprene, acidifying the ammonium sulfate seed aerosol present in the reaction chamber. Kroll et al. [2005, 2006] obtained condensation of photooxidation products on seed particles at very low concentrations under high $\mathrm{NO}_{\mathrm{x}}$ conditions and in the absence of $\mathrm{NO}_{\mathrm{x}}$. Yields amounted to $0.9-5.5 \%$ for $10-$ $500 \mathrm{ppb}$ of isoprene.

[4] Oligomerization within SOA has recently been detected in the presence of acidic and neutral seed particles and in their absence [Gao et al., 2004a, 2004b; Hoffmann et al., 2002; Iinuma et al., 2004; Tolocka et al., 2004; Ziemann, 2002] from the ozonolysis of $\alpha$-pinene and other unsaturated hydrocarbons as well as from the photooxidation of $\mathrm{NO}_{\mathrm{x}}$ with 1,3,5-trimethylbenzene or $\alpha$-pinene [Baltensperger et al., 2005; Kalberer et al., 2004]. Measurements with an aerosol mass spectrometer by Kroll et al. [2006] also indicated the formation of oligomers in aerosols from isoprene photooxidation. Oligomerization results in molecules with a higher molecular weight and thus lower vapor pressure. It can enable partitioning of highly volatile molecules into the aerosol phase, which otherwise would be expected to be found only in the gas phase. Thus, oligomerization has the potential to increase the aerosol yield of known precursors, but even more so, to enhance the SOA formation potential of precursors that have up to now been considered to have very little aerosol formation potential such as isoprene. In this study we show that isoprene photooxidation produces oligomers by mass spectrometry and volatility measurements.

\section{Experiment}

[5] Photooxidation experiments were carried out in a $27-\mathrm{m}^{3}$ Teflon chamber at $20^{\circ} \mathrm{C}$ and $0-85 \%$ relative humidity [Paulsen et al., 2005]. The chamber was first humidified before introducing $\mathrm{NO}$ and $\mathrm{NO}_{2}$. A known amount of isoprene (Fluka, 99.5\%) was evaporated in a heated glass sampling bulb and continuously flushed with pure air into the chamber and allowed to equilibrate for $30 \mathrm{~min}$. Four xenon arc lamps were used to simulate the solar light spectrum and start the photochemistry. No seed particles were used.

[6] Isoprene and the oxidation products methylvinylketone (MVK) and methacrolein (MACR) were monitored 


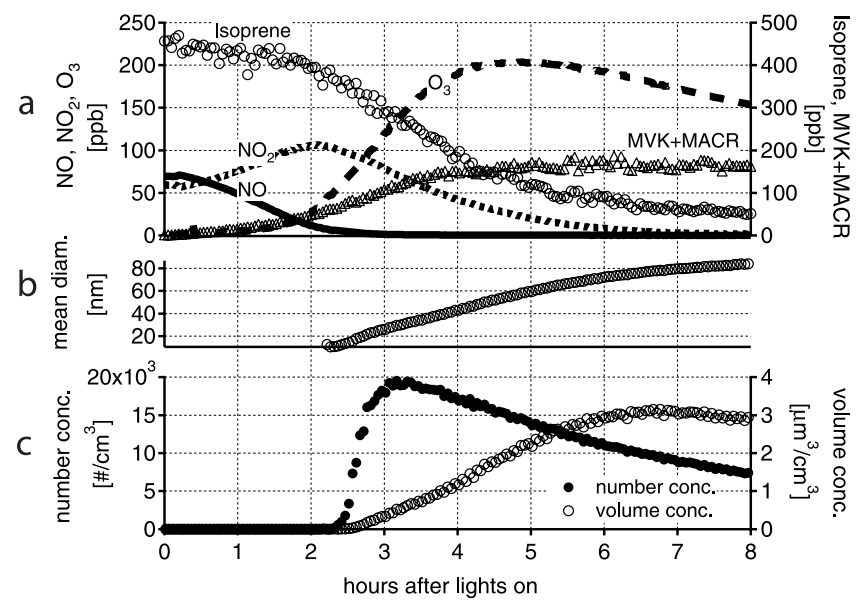

Figure 1. Temporal profile (Table 1, Exp. 6) of: (a) isoprene, $\mathrm{NO}, \mathrm{NO}_{2}$, Ozone $\left(\mathrm{O}_{3}\right), \mathrm{MVK}+\mathrm{MACR}$, (b) particle geometric mean diameter, (c) particle number concentration, particle volume concentration (uncorrected for wall loss).

using proton-transfer-reaction mass spectrometry (PTRMS). Ozone was measured with a commercial Environics S300. NO and $\mathrm{NO}_{2}$ were quantified with a Thermo Environmental Instruments $42 \mathrm{C}$ trace level, which was equipped with a photolytic converter (Blue light Converter of Droplet Measurements Technologies, Boulder, $\mathrm{CO}$ ) to selectively reduce $\mathrm{NO}_{2}$ to $\mathrm{NO}$. The latter was then detected by $\mathrm{NO}+$ $\mathrm{O}_{3}$ chemiluminescence.

[7] Total particle number concentrations (diameter $\mathrm{Dp}>$ 3 and $>7 \mathrm{~nm}$ ) were monitored with condensation particle counters (CPC, TSI models 3025 and 3022A, respectively). Particle size distributions from 7 to $316 \mathrm{~nm}$ were measured with a scanning mobility particle sizer along with a TSI model 3010 CPC. Determination of the low volatility fraction was performed with a Volatility Tandem Differential Mobility Analyzer (VTDMA), based on the size reduction of the aerosol due to evaporation at different temperatures [Paulsen et al., 2006]. The residence time of the aerosol in the heater was one second. A dryer was mounted in front of the VTDMA to avoid shrinking of particles due to evaporation of water rather than of volatile organics.

[8] Matrix assisted laser desorption/ionization mass spectrometry (MALDI-MS) was performed off-line after aerosol sampling on $10-\mathrm{mm}$ stainless steel plates coated with graphitized carbon $(2 \mu \mathrm{m}$ particles, Aldrich) in an 11-stage impactor [Maenhaut et al., 1996]. The MALDI plates were placed on stage three of the impactor at a pressure of approximate $600 \mathrm{hPa}$. After sampling of $0.7-1.5 \mathrm{~m}^{3}$ of air the plates were placed directly on the sample holder of the mass spectrometer and measured without further treatment with a time-of-flight mass spectrometer (Axima-CFR, KRATOS Analytical Shimadzu, laser wavelength $337 \mathrm{~nm}$ ) [Kalberer et al., 2006].

\section{Results and Discussion}

[9] The photooxidation of isoprene and $\mathrm{NO}_{\mathbf{x}}$ leads to the formation of ozone, oxidized volatile organic compounds (VOC) and SOA. Figure 1 shows the typical temporal evolution of the precursors, ozone and the sum of MVK and MACR as well as the aerosol number and volume concentration observed in experiment 6 (Table 1). After the start of the irradiation isoprene decreases slowly during the first two hours before a stronger decrease occurs, which coincides with the maximum of $\mathrm{NO}_{2}$ and a strong increase in the ozone concentration. MVK+MACR (PTR-MS measures their sum concentration since they have the same molecular weight) are formed slowly in the beginning and increase sharply after two hours when isoprene reacts more rapidly. These two oxidation products reach a maximum after about 6 hours and start to decrease slowly from then on. Nucleation occurs after 2.5 hours, about half an hour after the decay of isoprene has accelerated. Particles grow steadily to $80 \mathrm{~nm}$ within 8 hours mainly due to condensation and after that the mean diameter increases due to coagula-

Table 1. Experimental Conditions and Results

\begin{tabular}{cccccccc}
\hline Exp. No. & {$[\text { Isoprene }]_{0}, \mathrm{ppb}$} & {$[\mathrm{NO}]_{0}, \mathrm{ppb}$} & {$\left[\mathrm{NO}_{2}\right]_{0}, \mathrm{ppb}$} & {$\left[\mathrm{O}_{3}\right]_{\max }, \mathrm{ppb}$} & $\mathrm{RH}, \%$ & $\mathrm{SOA} \mathrm{Mass}^{\mathrm{a}} \mu \mathrm{g} / \mathrm{m}^{3}$ & $\mathrm{SOA} \mathrm{Yield}^{\mathrm{a}, \mathrm{b}}$ \\
\hline $1^{\mathrm{c}}$ & 180 & 38 & 41 & 158 & 47 & 1.0 & 0.002 \\
2 & 203 & 0 & 40 & 100 & 51 & 0.7 & 0.002 \\
$3^{\mathrm{c}}$ & 351 & 83 & 83 & 214 & 52 & 5.0 & 0.006 \\
$4^{\mathrm{c}}$ & 368 & 63 & 81 & 175 & 84 & 3.7 & 0.004 \\
$5^{\mathrm{c}}$ & 451 & 82 & 87 & 192 & 51 & 12.9 & 0.013 \\
6 & 470 & 70 & 60 & 203 & 53 & 10.0 & 0.009 \\
$7^{\mathrm{c}}$ & 473 & 60 & 40 & 234 & $<2$ & 22.6 & 0.019 \\
$8^{\mathrm{c}}$ & 473 & 63 & 52 & 250 & 9 & 9.2 & 0.007 \\
$9^{\mathrm{c}}$ & $\sim 480^{\mathrm{d}}$ & 80 & 82 & 235 & $<2$ & 16.8 & $\sim 0.014$ \\
$10^{\mathrm{c}}$ & $\sim 480^{\mathrm{d}}$ & 96 & 82 & 257 & 52 & 9.6 & $\sim 0.008$ \\
$11^{\mathrm{c}}$ & 504 & 75 & 89 & 250 & $<2$ & 17.5 & 0.013 \\
$12^{\mathrm{c}}$ & 836 & 285 & 294 & 391 & 50 & 86.5 & 0.039 \\
$13^{\mathrm{c}}$ & 1105 & 251 & 240 & 337 & 53 & 50.7 & 0.019 \\
14 & 1716 & 408 & 417 & 450 & 50 & 177.4 & 0.039 \\
15 & 1776 & 446 & 488 & 458 & 49 & 217.0 & 0.047 \\
$16^{\mathrm{c}, \mathrm{e}}$ & 2085 & 540 & 806 & 486 & 52 & 267.9 & 0.049 \\
$17^{\mathrm{e}}$ & $\sim 2500^{\mathrm{d}}$ & 700 & 724 & 531 & 52 & 336 & $\sim 0.053$ \\
\hline
\end{tabular}

${ }^{\mathrm{a}}$ Determined at the time of the measured maximum particle volume concentration, corrected for wall loss, assuming a density of $1.4 \mathrm{~g} / \mathrm{cm}^{3}$.

${ }^{\mathrm{b}}$ Aerosol mass concentration to the mass concentration of isoprene consumed.

${ }^{\mathrm{c}}$ VTDMA measurements done.

${ }^{\mathrm{d}}$ Isoprene mixing ratio not measured, estimated from amount of input.

${ }^{\mathrm{e}}$ MALDI measurements done. 


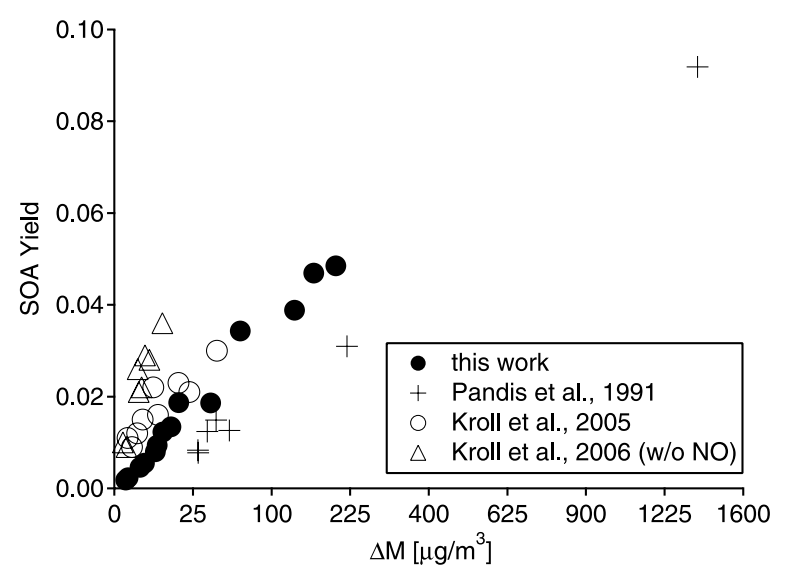

Figure 2. Summary of SOA yields from literature and this work as a function of organic mass concentration. A density of $1.4 \mathrm{~g} \mathrm{~cm}^{-3}$ was applied to the data of Pandis et al. [1991] which are uncorrected for wall loss. The x-coordinate has a square-root scale for better overview.

tion and size dependent wall losses, as verified by regression analysis of the General Dynamic Equation using the method developed by Verheggen and Mozurkewich [2006]. The aerosol volume reaches a maximum after about 6.5 hours and then decreases due to wall losses as seen in the number concentration.

[10] Experimental conditions and results are given in Table 1. The SOA yield was determined at the time of measured maximum aerosol volume. The SOA volume was corrected for wall losses by applying a first order loss coefficient obtained from the decay of the particle number concentration after reaching its maximum value for each individual experiment. A density of $1.4 \mathrm{~g} / \mathrm{cm}^{3}$ was estimated from a comparison of the mobility diameter obtained from DMA measurements and the vacuum aerodynamic diameter measured by the aerosol mass spectrometer. Blank experiments without addition of precursors typically produced less than $0.5 \mu \mathrm{g} / \mathrm{m}^{3} \mathrm{SOA}$. This possible background contribution was not subtracted from the values in Table 1. Such a correction would be of most importance for the lowest $200 \mathrm{ppb}$ isoprene experiment, where its contribution could be on the order of $50 \%$. The PTR-MS signal also revealed a terpene impurity in the isoprene sample which was not further identified. Its contribution to the SOA yield was estimated from the yield measurements by Griffin et al. [1999] for $\beta$-pinene and limonene, two terpenes forming SOA with high yield. Using those yields at our measured SOA mass for the low isoprene concentration experiments we calculated a potential contribution of the reacted terpene impurity of less than $8 \%$. Figure 2 compares the aerosol yields obtained in our work with those of Pandis et al. [1991] and Kroll et al. [2005, 2006]. Our data lie within a factor of two between those of Pandis et al. [1991] and Kroll et al. [2005]. The former experiments were carried out in an outdoor chamber under dry conditions and relatively high temperatures of more than $30^{\circ} \mathrm{C}$, whereas our experiments were performed at $20^{\circ} \mathrm{C}$. Thus lower SOA yields may be expected due to less partitioning of semi-volatiles. Additionally, those data were not corrected for wall loss. The experiments of Kroll et al. [2005] were performed at very low $\mathrm{VOC} / \mathrm{NO}_{\mathrm{x}}$ ratios with $\mathrm{HONO}$ as $\mathrm{OH}$ radical precursor. Additional experiments by Kroll et al. [2006] at no $\mathrm{NO}_{\mathrm{x}}$ but with $\mathrm{H}_{2} \mathrm{O}_{2}$ as $\mathrm{OH}$ radical precursor produced much larger SOA yields. This might be explained with a high hydroperoxy radical formation under such conditions which may also react with isoprene and some products.

[11] It is difficult to study SOA formation in a smog chamber at atmospherically relevant concentrations of isoprene and $\mathrm{NO}_{\mathrm{x}}$. Wall losses of condensable species delay or inhibit nucleation, and wall losses of aerosol particles keep the concentration very low. Additionally, the background aerosol concentration might be of similar magnitude or even larger than the SOA yield from isoprene. One way to overcome this is to speed up the reaction chemistry to induce fast nucleation as shown by Kroll et al. [2005, 2006]. However, the choice of the $\mathrm{OH}$ radical source seems to

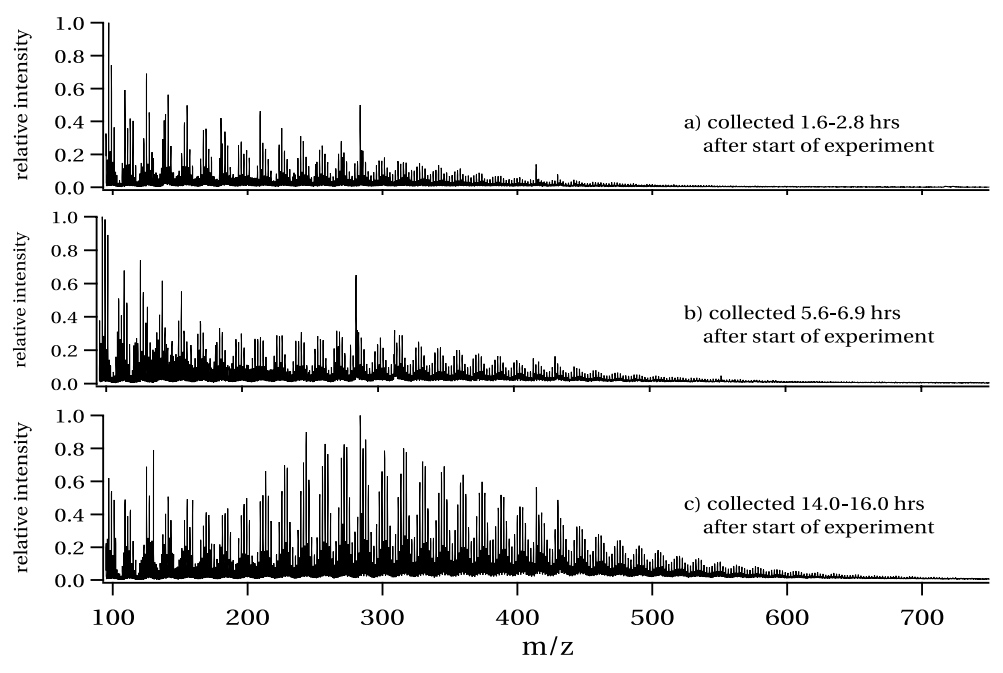

Figure 3. MALDI mass spectra of aerosol collected on steel plates in an impactor (Table 1, Exp. 17). Mass spectra were normalized to the most intense peak. The particle mass present in the smog chamber during the collection times was 81, 198 and $114 \mu \mathrm{g} / \mathrm{m}^{3}$ for Figures $3 \mathrm{a}, 3 \mathrm{~b}$ and 3c, respectively. Nucleation started after $65 \mathrm{~min}$. 


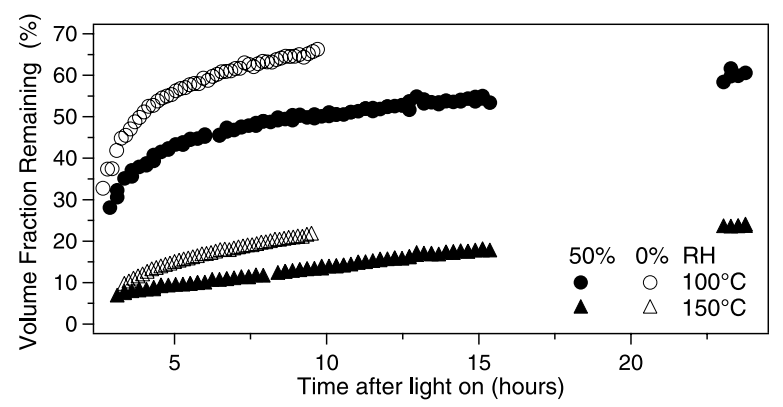

Figure 4. Volatility of isoprene aerosol at different temperatures as a function of irradiation time. The experiments were performed at nominally 0 (Table 1 , exp. 9) and $50 \%$ (Exp. 10) relative humidity. Simultaneous measurements at different diameters yielded identical VFR.

influence the SOA yield. In case of HONO as an efficient $\mathrm{OH}$ radical source $\mathrm{NO}_{\mathrm{x}}$ concentrations are also higher than is typical for ambient conditions.

[12] Since relative humidity encompasses a wide range under ambient conditions, we also explored its influence on SOA yield and properties. Experiments performed at different relative humidities ( 0 to $85 \%$ ) showed similar aerosol yields within experimental uncertainty (Table 1).

[13] Figure 3 shows MALDI-MS spectra of isoprene SOA collected between 1.6-2.8, 5.6-6.9 and 14.016.0 hours after start of irradiation. Already after 2 hours high mass peaks were observed. These grow in intensity with time relative to lower mass compounds, and still higher mass peaks start to appear. A regular pattern between $\mathrm{m} / \mathrm{z}$ 100 and 600 with mass differences of 14,16 or 18 is observed, typical of a polymeric substance. The first mass spectrum was taken during the rapid consumption of isoprene and before MVK+MACR and the aerosol volume reach the maximum concentration while afterward isoprene was mostly consumed and MVK+MACR and the aerosol volume decreased. According to Kroll et al. [2005, 2006] mainly the oxidation of methacrolein contributes to SOA formation.

[14] The isoprene oligomers grew slowly in size as the number average molecular weight $\left(M_{n}\right)$ and weight average molecular weight $\left(\mathrm{M}_{\mathrm{w}}\right)$ increased gradually over time from 310 to $360 \mathrm{Da}$ and 350 to $400 \mathrm{Da}$, respectively. The polydispersity index $\left(\mathrm{PI}=\mathrm{M}_{\mathrm{w}} / \mathrm{M}_{\mathrm{n}}\right)$ varies for isoprene SOA between 1.11 and 1.16 without obvious time trend and shows thus a very narrow chain length distribution. We conclude that the relative amount of oligomers and their molecular weight increase with time, however, the absolute amount of oligomers in the SOA cannot be determined since MALDI-MS is not a quantitative method.

[15] The formation of oligomers was further supported by volatility measurements. Figure 4 presents the volume fraction remaining (VFR) of the aerosol at 100 and $150^{\circ} \mathrm{C}$ and at 0 and $50 \%$ RH. The continuous increase of the VFR over 25 hours indicates that the aerosol becomes less volatile over time. At $100^{\circ} \mathrm{C}$ a fast increase of the VFR from 27 to $44 \%$ occurs over the first 5 hours and then steadily increases to $62 \%$. At $150^{\circ} \mathrm{C}$ a steady increase from 5 to $25 \%$ is measured. This decrease of volatility can be caused both by oxidation of the species and by reactions in the aerosol phase like addition or condensation of two compounds forming a higher molecular weight species. The MALDI-MS result favors the latter explanation. For dry experiments the decrease of volatility is even more pronounced. Since a dryer was mounted in front of the VTDMA condensed water on the particles can be ruled out as an explanation. At present, we can only speculate on the cause of this effect. Lower volatile oxidation products due to the reaction of the Criegee intermediate from isoprene ozonolysis with other compounds than water may be formed. The lower humidity may also increase the acidity in the condensed phase since the organic acids are less diluted, which would enhance oligomerization. However, this should also lead to higher SOA yields. This is not the case, however, the SOA yield measurements might not be accurate enough to resolve this effect. Another reason could also be a change of solubility with less water, or different chemical composition which influences the partitioning of semi-volatile species. A decrease of the partitioning also occurs when the average molecular weight increases. Thus, the reason for this humidity effect on the aerosol volatility needs further investigation.

[16] The oligomer formation in aerosols may lead to significantly higher aerosol yields than estimated from equilibrium partitioning. This process may support the uptake of compounds that have high vapor pressure into the aerosol phase. Hence, oxidation products of small molecules such as isoprene may still be an important contributor to global SOA formation in view of its large source strength. From the results presented here it is still not possible to estimate the isoprene SOA yield under ambient conditions, as the initial concentrations were still much too high. It is a great challenge to perform experiments under realistic ambient conditions or to mimic those reasonably well. If oligomerization reactions are determining the amount of isoprene oxidation products taking part in SOA formation the chemical environment might also strongly influence the aerosol yield. The incorporation of oxidation products of other precursors may favor oligomerization, as does the aerosol acidity as already shown by Gao et al. [2004a].

[17] Acknowledgments. This work was supported by the Swiss National Science Foundation (20020-108095/1), as well as by the European Commission (EUROCHAMP, FP6-505968).

\section{References}

Baltensperger, U., et al. (2005), Secondary organic aerosols from anthropogenic and biogenic precursors, Faraday Discuss., 130, 265-278.

Claeys, M., et al. (2004), Formation of secondary organic aerosols through photooxidation of isoprene, Science, 303, 1173-1176.

Edney, E. O., T. E. Kleindienst, M. Jaoui, M. Lewandowski, J. H. Offenberg, W. Wang, and M. Claeys (2005), Formation of 2-methyl tetrols and 2 -methylglyceric acid in secondary organic aerosol from laboratory irradiated isoprene/ $\mathrm{NO}_{\mathrm{x}} / \mathrm{SO}_{2} /$ air mixtures and their detection in ambient PM2.5 samples collected in the eastern United States, Atmos. Environ., $39,5281-5289$.

Gao, S., M. Keywood, N. L. Ng, J. Surratt, V. Varutbangkul, R. Bahreini, R. C. Flagan, and J. H. Seinfeld (2004a), Low-molecular-weight and oligomeric components in secondary organic aerosol from the ozonolysis of cycloalkenes and alpha-pinene, J. Phys. Chem. A, 108, 10,14710,164 .

Gao, S., et al. (2004b), Particle phase acidity and oligomer formation in secondary organic aerosol, Environ. Sci. Technol., 38, 6582-6589.

Griffin, R. J., D. R. Cocker III, R. C. Flagan, and J. H. Seinfeld (1999), Organic aerosol formation from the oxidation of biogenic hydrocarbons, J. Geophys. Res., 104, 3555-3567.

Guenther, A., et al. (1995), A global model of natural volatile organic compound emissions, J. Geophys. Res., 100, 8873-8892. 
Hoffmann, T., R. Bandur, S. Hoffmann, and B. Warscheid (2002), On-line characterization of gaseous and particulate organic analytes using atmospheric pressure chemical ionization mass spectrometry, Spectrochim. Acta Part B-At. Spectrosc., 57, 1635-1647.

Iinuma, Y., O. Boge, T. Gnauk, and H. Herrmann (2004), Aerosol-chamber study of the alpha-pinene $/ \mathrm{O}_{3}$ reaction: Influence of particle acidity on aerosol yields and products, Atmos. Environ., 38, $761-773$.

Kalberer, M., et al. (2004), Identification of polymers as major components of atmospheric organic aerosols, Science, 303, 1659-1662.

Kalberer, M., M. Sax, and V. Samburova (2006), Molecular size evolution of oligomers in organic aerosols collected in urban atmospheres and generated in a smog chamber, Environ. Sci. Technol., in press.

Kamens, R. M., M. W. Gery, H. E. Jeffries, M. Jackson, and E. I. Cole (1982), Ozone-isoprene reactions - Product formation and aerosol potential, Int. J. Chem. Kinet., 14, 955-975.

Kroll, J. H., N. L. Ng, S. M. Murphy, R. C. Flagan, and J. H. Seinfeld (2005), Secondary organic aerosol formation from isoprene photooxidation under high- $\mathrm{NO}_{x}$ conditions, Geophys. Res. Lett., 32, L18808, doi:10.1029/2005GL023637.

Kroll, J. H., N. L. Ng, S. M. Murphy, R. C. Flagan, and J. H. Seinfeld (2006), Secondary organic aerosol formation from isoprene photooxidation, Environ. Sci. Technol., 40, 1869-1877.

Limbeck, A., M. Kulmala, and H. Puxbaum (2003), Secondary organic aerosol formation in the atmosphere via heterogeneous reaction of gaseous isoprene on acidic particles, Geophys. Res. Lett., 30(19), 1996, doi:10.1029/2003GL017738.

Maenhaut, W., R. Hillamo, T. Makela, J. L. Jaffrezo, M. H. Bergin, and C. I. Davidson (1996), A new cascade impactor for aerosol sampling with subsequent pixe analysis, Nucl. Instrum. Methods Phys. Res. B, 109110, 482-487.

Matsunaga, S. N., C. Wiedinmyer, A. B. Guenther, J. J. Orlando, T. Karl, D. W. Toohey, J. P. Greenberg, and Y. Kajii (2005), Isoprene oxidation products are a significant atmospheric aerosol component, Atmos. Chem. Phys. Disc., 5, 11,143-11,156.

Pandis, S. N., S. E. Paulson, J. H. Seinfeld, and R. C. Flagan (1991), Aerosol formation in the photooxidation of isoprene and $\beta$-pinene, Atmos. Environ., 25, 997-1008.

Paulsen, D., J. Dommen, M. Kalberer, A. S. H. Prévôt, R. Richter, M. Sax, M. Steinbacher, E. Weingartner, and U. Baltensperger (2005), Secondary organic aerosol formation by irradiation of 1,3,5-Trimethylbenzene$\mathrm{NO}_{\mathrm{x}}-\mathrm{H}_{2} \mathrm{O}$ in a new reaction chamber for atmospheric chemistry and physics, Environ. Sci. Technol., 39, 2668-2678.

Paulsen, D., E. Weingartner, M. R. Alfarra, and U. Baltensperger (2006), Volatility measurements of photochemically and nebulizer-generated organic aerosol particles, J. Aerosol Sci., doi:10.1016/j.jaerosci. 2005.08 .004 , in press.

Tolocka, M. P., M. Jang, J. M. Ginter, F. J. Cox, R. M. Kamens, and M. V. Johnston (2004), Formation of oligomers in secondary organic aerosol, Environ. Sci. Technol., 38, 1428-1434.

Verheggen, B., and M. Mozurkewich (2006), An inverse modeling procedure to determine particle growth and nucleation rates from measured aerosol size distributions, Atmos. Chem. Phys. Disc., 6, 1679-1723.

Ziemann, P. J. (2002), Evidence for low-volatility diacyl peroxides as a nucleating agent and major component of aerosol formed from reactions of $\mathrm{O}_{3}$ with cyclohexene and homologous compounds, J. Phys. Chem. A, $106,4390-4402$.

M. R. Alfarra, U. Baltensperger, J. Dommen, J. Duplissy, A. Gascho, A. Metzger, A. S. H. Prevot, B. Verheggen, and E. Weingartner, Laboratory of Atmospheric Chemistry, Paul Scherrer Institut, CH-5232 Villigen, Switzerland. (josef.dommen@psi.ch)

M. Kalberer, Department of Chemistry and Applied Biosciences, Swiss Federal Institute of Technology (ETH) Zurich, CH-8093 Zurich, Switzerland. 